\title{
Quality Framework of Higher Education in Vietnam, Malaysia and Nigeria
}

\author{
Nguyen Duc Hanh ${ }^{1}$, Vu Quynh Loan ${ }^{2} \&$ Nguyen My Viet ${ }^{2}$ \\ ${ }^{1}$ Dai Nam University, Ha Noi, Viet Nam \\ ${ }^{2}$ Tan Trao University, Tuyen Quang, Viet Nam \\ Correspondence: Nguyen Duc Hanh, Dai Nam University, Ha Noi, Viet Nam. E-mail: duchanh.xafs@ gmail.com
}

Received: February 4, 2020

doi:10.5539/hes.v10n2p133
Accepted: April 1, $2020 \quad$ Online Published: April 6, 2020

URL: https://doi.org/10.5539/hes.v10n2p133

\begin{abstract}
The purpose of this study is to investigate how Vietnam, Malaysia and Nigeria quality assurance agencies operate towards ensuring quality in higher education institutions. Quality assurance systems was investigated with respect to social demands and it was compared based on the key concepts: autonomy, accountability and improvement. The study relied on qualitative document analysis methods and was conducted on relevant higher education and policy, quality assurance systems of Viet Nam Ministry Education and Training, quality assurance of National Universities Commission, National Board for Technical Education of Nigeria and Malaysian Qualification Agency respectively and their challenges were assessed and compared. There are deals of convergence between Quality Assurance systems of Viet Nam, Malaysia and Nigeria. Viet Nam and Malaysia has a single Quality Assurance system while Nigeria has multi Quality Assurance systems. In all three countries' Quality Assurance systems made achievements in terms of autonomy, accountability and improvement. In Vietnam, Vietnamese Qualification Agency: internal Quality Assurance is embedded within an accreditation system, but still requires a recognition external quality assurance agency. In Malaysia, Malaysian Qualification Agency: internal Quality Assurance is embedded within accreditation system and reduced the involvement of external Quality Assurance agency. In Nigeria, the National Universities Commission, National Board for Technical Education and National Commission for Colleges of Education of Nigeria provides guidelines for higher education institutions to assist build their internal Quality Assurance. Vietnam and Malaysia Quality Assurance experienced accountability being demonstrated for continuous improvement while Nigeria Quality Assurance accountability is seen with invisible improvement due to challenges associated with the quality frameworks. The study gives appreciated vision into Quality Assurance systems and frameworks of higher education institutions and how Quality Assurance responds to the social demands of stakeholders.
\end{abstract}

Keywords: quality framework; autonomy; accountability; improvement; higher education.

\section{Introduction}

In the last decades, the dramatic economic, political and social changes have led to significant changes in higher education institutions, more expansion, more populated, competing with each other and always innovating. This is because of the reductions in funding where higher education institutions are experiencing and there are agitating for autonomous in their management of finance and resource, this required the higher education institutions to be more accountable in management of their finances, resources and academic teaching and learning results for quality services delivery through Quality Assurance (QA) processes. However, to ensure the quality of higher education institution providers, there are need to increase the demands of efficient evaluation tools to measure the institution's success in terms of programs and the competences of the graduates on and or at the completion of their programs (Kromydas, 2017).

In higher education institutions around the globe, the most important change driver was the emergence of QA with various QA agencies which functioned as evaluation and or accreditation tools to regulate and to intervene in the quality based objectives of the institutions (Jarvis, 2017). QA agency for higher education institutions is a body that checks on standards and quality, review and conducts a quality assessment, develops reference points and guidance for providers and researches relevant issues. Therefore, QA can enhance and ensure compliance in students learning outcomes in higher education institutions. A Question frequently raised about the incompatibility between QA purposes, improvement and accountability as reflected in the QA methodology of 
this study (Williams, 2016). QA approaches vary from country to country, most external QA systems includes: accreditation, evaluation, audit, review and approval. External QA refers to the action of an external body possibly a QA agency, it assess the operation of the institutions or its programs to determine whether it is meeting the agreed standards (Machumu \& Kisanga, 2015). External QA also focuses on the accreditation approaches and stressing compliance to quality enhancement and aim to achieve accountability and enhance institution's performance. Internal QA system according to UNESCO (2013) (Machumu \& Kisanga, 2015), refers to institution or program's policies and mechanisms for ensuring fulfilling its purposes, as well as the standards that apply to higher education. Internal QA focuses on teaching and learning quality improvement while external QA focus on external accountability to stakeholders and the public for quality improvement. Internal QA refers to as an evaluation initiative for or by people within an institution and the external QA as an evaluation undertaken by government or agencies and or stakeholders (Geven \& Maricut, 2015).

To enhance accountability and social responsibility in a higher education institution, QA agencies have to be transparent in their exercises. This is because the societies should know the activities about the institution by disclosing the institutions' learning outcomes, learning opportunities, graduate employment and the assessment procedures. The dynamic concepts in higher education's QA are accountability, improvement, transparency and autonomy. Therefore, looking at the aforementioned concepts stated above there are interrelated as such inadequate funding in an institution by the government resulted in the higher education institutions agitating for autonomous which consequently will require the institutions to be more accountable to the societies. According to the existing documents in USA addressed the criticism that accreditation seeking for accountability end up undermines the autonomy of institution; accreditation should not diminish the autonomy of the higher education institution, transparency has become a key principle for QA and has interacted with accountability (Noda et al., 2018). Therefore, QA is always geared towards improvement even if its function is for accountability in the higher education system.

The Vietnamese government encourages universities to increase their autonomy and self-accountability to society in terms of their demands. Internal QA was enshrined to improve institutions' quality through self-evaluation, self-accreditation, educational assessment and student and staff feedback, and is the basis for external QA system to assess and accredit for universities (Higher education law, 2018). Malaysian government encouraged higher education institutions in terms of their demands. The term internal QA was enshrined to improve institutions' quality through self- evaluation, self-accreditation, educational assessment and student/staff feedback. The proposed internal QA mechanism complement the existing internal and external QA mechanism at higher a education institution (Endut et al., 2018). In Nigeria the term internal QA was first mentioned in line with the higher education systems, the proposal stated that the initial responsibility of improving the quality of higher education institution lay with the institutions themselves. The spirit of standards and quality into the Nigerian higher education system is accrediting programs that came into existing through provisions of Decree No 16 of 1985 of Nigerian universities (Asiyai, 2015), the main purpose of QA agencies in many subs- Saharan Africa countries including Nigeria seems to be licensing and regulation rather than for quality improvement because of non-compliance of government towards funding (Odukoy et al., 2018).

Vietnam, Malaysia and Nigeria all have a higher education systems and policies guiding and managing the institutions from pre-school to university level. They have both a QA system for accreditation and regulating educational institutions. All three countries have social issues and there are third world countries use their higher education to improve teaching, learning and research. Vietnam has established a QA system under the management of the Ministry of Education and Training (Vietnam Quality Assurance - VQA), QA system includes centers of quality accreditation of regional universities and center QA of Vietnam association of universities and colleges, an independent accrediting organization. Therefore, QA of Vietnam interacts with educational institutions on the principles of responsibility, accountability and transparency and reviewing regularly to updating core activities to ensure continuous improvement. Malaysia, established a single QA system known as MQA (Malaysia Quality Assurance) that gives mandate to ensure QA of public and private institutions. MQA also works according to the principle that interacts with institutions for responsibility, transparency and reviewing regularly to updating core activities to ensure continuous improvement. Nigeria, have multi-QA agency namely: National Universities Commission (NUC), National Board for Technical Education (NBTE) and National Commission for Colleges of Education (NCCE), they were established for accrediting and regulating the QA system in their respective institutions. In Nigeria also the QA agencies interact with institutions for accountability and transparency, and to ensure improvement. Therefore, the QA concepts transformed the QA frameworks to respond to changing social demands of societies.

However, the higher education systems in Malaysia has responded to internationalization and technological 
innovation, Vietnam has started towards international standards in higher education while Nigeria higher education systems were underfunded. Though, there has been little research on actual QA conditions, but globalisation that imposed pressures on economic development, as science and innovations in technology that creates opportunities for individuals is a mirage. And as far as to my awareness, there have been no bases for comparison of Vietnam, Malaysia and Nigeria in terms of QA practices.

\section{Overview of Higher Education Systems and Policies in Vietnam, Malaysia and Nigeria}

This part of the study gives an overview of the higher education systems and policy, QA system development and QA frameworks in Vietnam, Malaysia and Nigeria.

\subsection{Higher Education System and Policy in Vietnam}

The education system in Vietnam begins from pre-school to higher education, and is regulated and management by the Ministry of Education and Training. The national education system was implemented after was passed by Parliament and Ministry of education and training has issued a common curriculum framework for all educational levels. Ministry of Labour, War invalids and Social Affairs issues a common vocational training framework with college, intermediate and vocational levels. Higher education in Vietnam is formulated through public and private institutions. Currently, the total number of universities, institutes and colleges in Vietnam is nearly 700 institutions, in which the higher education system has 237 universities and institutes (including 172 public schools, 60 private and private schools, 5 schools with $100 \%$ foreign capital), 37 scientific research institutes were assigned the task of doctoral training, 31 pedagogical colleges and 2 pedagogical secondary schools, and has 23 universities were granted autonomous status which has been operationalised into financial, human resource, institutional and academic autonomy. The issue of autonomy in public universities is to closely relate to the plan for gradual reduction of financial support from the government (Ministry of Education and Training).

Pre-school education is compulsory, and the other levels of study are encouraged in Vietnam, it was reported of Vietnamese Ministry of Education and Training, at 2019 Vietnam has 5,36 millions of children pre-school level, 8,359 million students primary school, 5,603 million students secondary, 2,538 million students high school level, and 1,443 million students in universities (Ministry of Education and Training). The admission into tertiary institutions is controlled by a body known as Joint Admission Board of each university, through the national high school exam. This examination is compulsory for anyone who wishes to attend higher education institutions in Vietnam.

\subsection{Higher Education System and Policy in Malaysia}

Education in Malaysia also begins from pre-school to higher education. In Malaysia, the education system is regulated by the Ministry of Education. National Education System was implemented after the education Acts 1966 was passed by parliament to foster unity and nation-building through a common syllabus and curriculum (Grapragasem et al., 2014). Higher education in Malaysia is formulated through public and private institutions, Malaysia has 20 public universities, 24 polytechnics, 37 public community colleges, 33 private universities, five universities branch campuses and 500 private colleges (Grapragasem et al., 2014). Higher education is under the ministry of higher education, education enrolment in Malaysia is significant pre-school education is not compulsory, it was reported that almost 91percent of children were enrolled, primary school education enrolment is compulsory and the enrolment rate is $98 \%$. Secondary education enrolment rate of $90 \%$ in 2014, stated that at post-secondary education in 2016, 20,232 students were enrolled in public community colleges, 99,551 students in public polytechnics, 695,026 in private higher education institutions (including colleges, university colleges, universities) and 532,049 across the 20 public universities in Malaysia (Chang et al., 2018). As reported by MEBHE (Chang et al., 2018) has 12 universities were granted autonomous status which has been operationalised into financial, human resource, institutional and academic autonomy. The issue of autonomy in public universities is to closely relate to the plan for a gradual reduction of financial support from the government.

\subsection{Higher Education System and Policy in Nigeria}

The Nigerian system of education is regulated by the federal and state ministry of education. The education system starts from the pre-primary school level to university. At the tertiary level, it is divided into four segment institutions: universities, polytechnics/mono technics, colleges of education and innovative enterprise institutes (Kayode, 2018). The federal ministry of education was established to coordinates national policy on education, collect data for educational planning, maintains uniform standards of education, monitors the quality of education, harmonies the educational policies and procedures of the states develops curricula at the national level and cooperates with international agencies on a matter related to education (Kayode, 2018). To support the 
implementation of policies in the education system, there are government parastatal and institutions including; National Universities Commission (NUC). Each parastatal (government-owned utilities) ensures the provision of quality education in the educational sector under its jurisdiction (Commonwealth of Learning COL, 2017). National Commission for Colleges of Education (NCCE) provides advice to the ministry of education and coordinates all aspects of non-degree teacher education, National Board for Technical Education (NBTE) is a principal organ of the ministry of education created to handle all aspects of technical and vocational education falling outside university education national policy on education. The tertiary segments as of 2017 the NUC accredited 40 federal universities 44 state universities and 69 private universities as a degree granting institutions; the NBTE oversaw 28 federal polytechnics 41 state polytechnics 2 private polytechnics; 58 federal mono technics 32 state mono technics 8 private mono technics and 140 innovative enterprise institutions while the NCCE supervised non- university teacher with 21 federal colleges 49 state colleges and 82 private colleges of education (Commonwealth of Learning COL, 2017).

There has been a significant expansion of enrolment in Nigeria tertiary institutions, the market is large and diverse, its expansion has not kept pace with population and income growth and taken together with the macroeconomic slowdown and budget cuts public universities are unable to satisfy the rising demands for degree programs (Commonwealth of Learning COL, 2017). According to Joint Admission Matriculation Board (JAMB) (2016) (Commonwealth of Learning COL, 2017), 1.6 million secondary graduates took the matriculation examination and only 416,000 candidates were able to admit to public institutions leaving the private sector to absorb the remaining three-quarters of the students. However, because of the demands of candidates into university's degrees some colleges of education, colleges of technology and polytechnics started running degree affiliations to reduce the massification. In Nigeria, admission into tertiary institutions is controlled by a body known as JAMB through the conduct of the Unified Tertiary Matriculation Examination (UTME) (Kayode, 2018). This examination is compulsory for anyone who wishes to attend higher education institutions in Nigeria, with the exception of candidates who possess the advance level certificate and are given direct entry admission in the second year.

This study investigated the national agencies QA systems and frameworks used by the Vietnam, Malaysia and Nigeria in response to the social demands of their societies. This paper compared QA agencies' approaches to issues associated with autonomy, accountability and improvement. It also examined the issue between internal and external QA. Though the background information is on the higher education system, QA system development and challenges in the QA systems were examined. The QA policies and framework of Vietnam, Nigeria and Malaysia were analyzed and compared through the following questions:

(1) How did Vietnam, Malaysia and Nigeria QA framework respond to developing challenges?

(2) How did the external and internal QA balance institutional and programs accreditation challenges?

(3) How did the QA agencies balance between accountability and improvement?

This work has adopted a qualitative document analysis method. Document analysis is a systematic procedure for reviewing or evaluating document both printed and electronic (computer-based and the internet-transmitted) materials (Gross, 2018). Document analysis was conducted on relevant higher education and policy, QA systems, reports, evaluation guidelines, standards and indicators of VQA, NQA and MQA. Information was extracted from the developing issues QA in countries in a systematic manner and was examined for a comprehensive comparison. QA framework was examined for comparison to achieving the concepts: autonomy, accountability and improvement. The analysis also scrutinized QA approaches: internal and external in terms of institutional and programs.

\section{Results and Discussion}

\subsection{Vietnam, Malaysia and Nigeria Quality Assurance Systems}

QA of Vietnam, Malaysia and Nigeria is aiming to meet the increasing challenges of society, this content is reviewed through four main issues with each country.

For Vietnam, (1) VQA are evaluating higher education institutions, training programs to assist the internal quality assurance effectiveness in higher education and are a reference point for all qualifications in Vietnam. (2) VQA does respond to a change in higher education following the trends of the world for developing competency of labour through the quality of training. (3) The assessment is conducted every 5 years to enhance the standards of qualifications and serve the community better as well helping to facilitate the mobility workers and their integration within the ASEAN region and relevant to their industries' demands. (4) VQA respond to the challenges of accreditation of programs, qualifications and audit of the institutions of higher learning and or its 
components. This is to ensuring the quality of both public and private education programs in Vietnam.

In Malaysia, (1) MQA embarked on programs evaluation to assist the internal QA effectiveness in higher education and reference point for all qualifications. (2) MQA does respond to a shift in the higher education purposes and their delivery services for developing competency of labor through better quality of higher education and its products. (3) The review is made at periodic intervals for a comprehensive framework to enhance the standards of qualifications and serve the Malaysian community better as well helping to facilitate the mobility workers and their integration within the region and relevant to their industries' demands. (4) MQA respond to the challenges of accreditation of programs, qualifications and audit of the institutions of higher learning and or its components. This is to ensure the quality of both public and private education programs in Malaysia.

In Nigeria, (1) The NUC, NBTE and NCCE QA systems lack internal QA control which makes the institutions impossible to achieve their set objectives. (2) No respond to the shift in higher education purposes and the resources available for delivering educational services are inadequate to take care of the school-age population. (3) The review is made at a regular for a comprehensive framework of NUC, NBTE and NCCE to enhance standards but the QA manual is not yielded significant results on the communities. (4) The NUC, NBTE and NCCE response to challenges in terms of accreditations, the agencies are used to evaluate programs to determine compliance with minimum academic standards by each agency in Nigeria tertiary institutions.

\section{QA framework in Vietnam:}

Vietnam is located in the Southeast Asia region with the common principles designed by quality assurance agency in belonging to the ASEAN University Network - Quality Assurance (AUN-QA). AUN-QA activities carried under the Bangkok Agreement were adopted in 2000, providing a series of guidelines to promote the development of quality assurance systems as tools to maintain, improve and enhance the teaching, research, and overall learning standards of AUN member universities. In Vietnam, QA enhances quality assurance at all levels of study, higher educations institutions. Vietnam's external accrediting organizations include 5 centers in which one center QA of universities and Vietnam Association of Universities and Colleges, an independent accrediting organization. VQA decision and classifies qualifications based on a set of criteria that are approved nationally and benchmarked against international best practices, which earned academic levels, learning outcomes of study areas and credit system based on student academic load. VQA targets national and prefectural universities and emphasizes compliance with evaluation standards. The universities are in response to international trends in QA systems and accountability focusing more on learning outcomes, internal QA systems in teaching and learning and public information disclosure. This is through compliance to higher education institutions mission; teaching and research structure; academic staff and teaching support staff; student admissions; programs content and methods; learning outcomes, facilities and students support; internal teaching and learning QA system; finance and management and public information disclosure on teaching and learning (Ministry of Education and Training).

\section{QA framework in Malaysia:}

Malaysia is one among the Asia-pacific country with the common Chiba principles designed to guide both higher education institutions and quality assurance agencies. MQA enhances quality assurance at tier levels, Covers University, polytechnics and colleges/institutions. External QA in Malaysia began with the establishment of National Accreditation Board. Lembaya Akreditasi Negara (LAN) in 1997 to quality assurance programs. In 2007 LAN reorganized MQA to ensure the quality programs and qualifications offered in both public and private. As well as Vietnam, MQA transformed Malaysia's higher education from teacher centered to learners centered outcomes approach from programs compliance well as assist in strengthening internal QA practice. In 2013 MQA embarked on series of programs compliance evaluations to assist the level of compliance and effectiveness of internal QA of higher education and national reference point for all qualifications, and programs evaluation is meant to assist the academic levels and the degree fulfillment of institutions objectives (Vincenzi et al., 2018). Malaysia QA clarifies the qualification level, learning outcomes and credit system based on student learning load associated with the title of a qualification, no programme will be accredited unless it complies with the framework asset in the legislation (MQA, 2018). According to (COPPA, 2018), MQA is an instrument that develops and classifies qualifications based on a set of criteria that are approved nationally and benchmarked against international best practices, which earned academic levels, learning outcomes of study areas and credit system based on student academic load. In Malaysia, accreditation is carried out in three stages provisional accreditation, full accreditation and compliance evaluation. All accredited qualification is registered on the Malaysia qualifications register (MQR). Basic information on the qualifications, programs and awarding 
institution are stated in the register to have key information about programs. Code of Practice for Institution Audit (COPIA) serves for evaluation of the institutions as a whole (Mahbub, 2017; Ahmed et al., 2018).

\section{$Q A$ framework in Nigeria:}

The subject QA in higher education in Nigeria cannot be meaningfully addressed outside the context of the development of higher educational institutions. QA measure on market demands of graduates, admission in foreign universities, research and publication and institutional affiliations (Adetunji, 2018). In Nigeria the agencies or bodies that are responsible for QA are National Universities Commission NUC, National Board for Technical Education NBTE and National Commission for Colleges of Education NCCE. The agencies over the years are responsible for QA, the agencies have been doing these through programs regulation which entailed the enforcement of government regulation stipulating that for any Nigerian higher education institution to commence an academic programs or establish an academic unit it must obtain written approval from the respective agencies. Tertiary education institutions in Nigeria have enjoyed more provision for QA than lower levels with the establishment of NUC, NBTE and NCCE, each of the bodies is empowered to set up its mechanisms for QA for institutions under its supervision. The bodies from time to time draw up minimum academic standards in terms of floor space for lecturers, minimum library space, minimum staff/students ratio, minimum laboratories facilities/equipment per students, minimum teaching facilities/equipment and office, accommodation for effective teaching and learning in any given discipline. They include the stipulated curricula for the institutions as well as minimum entry and a graduation requirements for each discipline. Nigeria stated that accreditation in Nigeria higher education involve teams of experts from other institutions and engaged by the relevant agencies or commissions NUC, NBTE and NCCE to visit respective institutions at a given periodic internal every five years for the accreditation or re-accreditation of existing courses and programs (Adepoju, 2017). Monitoring, assessment/ evaluation are an instrument used by respective agencies /commissions to ensure that specific guidelines in the higher institution standards are closely monitored, assessed, evaluated and complied with. Another instruments employed by NUC, NBTE and NCCE to ensure QA in the respective institutions is the periodic review and of production of a document on minimum standards. The report of the moderation exercise is sent to the respective agencies NUC, NBTE and NCCE and institution's management, which guide the products of the institutions. However, in the Internal QA system: the existing frameworks lack internal QA control and standards that make the institutions impossible to achieve the set objectives stated by the National Policy on Education. The supervisory bodies of the federal ministry of education and programs accreditation NUC, NBTE and NCCE play a form of quality control roles but said to be too macro (Unimna \& Unimke, 2018). The federal government through the ministry of an education established education trust fund (ETF) now called tertiary education trust fund (TETFund). This body support in infrastructural development in tertiary institutions. Industrial training fund (ITF) was also established to bridge the gap between students theoretical and practical. Joint Admission and Matriculation Board (JAMB) responsible for conducting matriculation examinations known as PUTME (post unified tertiary and matriculation examination). All these agencies were established to ensuring QA and standards but failed because of no proper supervision, funding and politics surrounding the systems (Adepoju, 2017).

\subsection{Comparison External and Internal QA Balances Conditional, Institutional and Programs Accreditation Challenges}

\section{QA system in Vietnam:}

(1) QA system in Vietnam includes internal accreditation and external accreditation. Internal accreditation indicates conditions fulfilled the minimum requirement of institutions, external independent accreditation institutions evaluate and validate the results. (2) The self- accreditation focuses on the capability and capacity of the internal QA system of an institution to evaluate all programs offered. (3) Internal QA mechanisms are selfevaluation of resources and activities in the teaching and learning process (Ministry of Education and Training).

\section{QA system in Malaysia:}

(1) QA system in Malaysia approaches involves around two ways. First, provision of accreditation which indicates programs fulfilled the minimum requirement. Secondly, institutions audits which are mostly self accreditation for programs meeting all criteria and standards. (2) The institutional audit which is self-accreditation focuses on the capability and capacity of the internal QA system of an institution to evaluate all programs offered. (3) Internal QA mechanisms are self-evaluation of resources and activities in the teaching and learning process.

QA system in Nigeria: 
(1) QA system in Nigeria is in one way external QA evaluates the operation of an institution or programs to ascertain the level of compliance. (2) Self- assessment system, institutions carry out an internal appraisal of its programs to ascertain the level of its internally set objectives and standards. (3) Internal QA mechanism is passive due to inadequate resources and it affects the quality delivery process.

\section{QA system challenges:}

QA system challenges for Vietnam and Malaysia are the same approaches that revolves around two approaches first is accredit programs and qualifications, secondly is institutional accreditation. In programme accreditation, it has two levels, first provision accreditation (internal) which indicates that programme has fulfilled the minimum requirement to be offered. Secondly, full accreditation is a confirmation that a programme met all the criteria and standards. Agree with the study (Tavares et al., 2017) and like Vietnam, in Malaysia accreditation of programs and qualification and institutional audit approaches to QA encourages reflection, have been proposed to help shift, its focus from monitoring and accountability towards the improvement of teaching and learning. Institutional audits take many forms but the highest form of the institutional audit is self- accreditation, focus on the capability and capacity of the internal QA system of an institution to evaluate academic programme offers (MQA, 2018). The higher education programme self-review (internal accreditation) and the MQA institutional audit (external quality accreditation).

According to (Endut et al., 2018), external QA mechanisms are subjected to the accreditation process, audit, ISO standards and peer reviews. The internal QA mechanisms are a self-evaluation of resources and activities in teaching and learning process, self-accreditation, educational assessment and students /staff feedback. The challenges associated to QA internal system is employee's' overlapping or increase workload due to quality management activities. Increase burden appears to have been given to administrative work given to the staff especially when she/he has a full teaching workload. Therefore, the gap of the understanding quality system among academic and non-academic staff need to be considered (Mokhtar et al., 2014) and (Mahbub, 2017). The autonomy concepts need to be determined and understood. Therefore, need to develop a clear functional definition and shared understanding. The institution has inadequately qualified quality management staff to undertake bigger challenges and tasks (Mokhtar et al., 2014).

On the issue of internal and external QA for Nigeria: external QA (agency, professional body) evaluates the operation of an institutional or its programs to ascertain the level of compliance with set minimum standards. Internal QA refers to the internal policies and mechanisms of institutions' programs for ensuring that it is fulfilling its purposes as well as the standards that apply to higher education in general (Banji, 2017). There is a self-assessment system in which the institution carries out an internal appraisal of its programs to ascertain the level of achievement of its internally set objectives and standards. Self - assessment is conducted at two levels, the programs and institutional levels, and the advisory of the administration of the level of permeation of quality in the operations and activities of the institution (Banji, 2017). University through its amended Act mandated the establishment of the internal QA department in all universities in 2005 in response to the quest for QA of the expanded higher education systems. In addition to the institutional and programs accreditation, university systems implemented self- accreditation to promote self- improvement to have autonomy and developing quality culture into the systems but not functional because of funding challenges. The private universities who were having adequate funding have adopted self- accrediting with internal QA mechanisms in place and were demonstrating academic accountability and improvement (Dada et al., 2017). Therefore, accountability in the area of QA in public universities is established with self-imposed behaviour and practices. Because of the challenges of funding fancy internal and external QAs, improvement has been a secondary feature. The challenges examined in Nigerian QA systems NUC, NBTE and NCCE all these periods are budgetary allocation, this accreditation exercise in Nigeria tertiary institutions are critical in achieving quality education. According to (Dada et al., 2017), adequate budgetary accreditation in the annual national budget would reduce the cost of sharing accreditation's expenditure with the institutions. Therefore, inadequate funding is the most critical challenges that threatened the attainment of quality in higher education institutions in Nigeria. Even the federal government of Nigeria and academic staff union of universities ASUU re-negotiation committee 2009 realised as widely acknowledge that the key to survival of Nigeria in 21 st century's ability to produce applied and theoretical knowledge in science, technology and humanities and hence renegotiation committee arrived at a consensus on the need for a rational and scientific procedure for determining the funding requiried to begin the revitalizing. Despite the efforts of ASUU, The Nigerian government has not shown enough commitment towards adequate funding of higher education (Asiyai, 2015) and (Unimna \& Unimke, 2018).

Overlapping of institution's policies and functions: in the case of the university also, the NUC establishment mandate was to coordinating and advising the federal government on matters relating to universities in Nigeria. 
As amendment demands, NUC was charged to cover accreditations and to ensure compliance with minimum academic standards, approval and establishment of new universities and programs (Dada et al., 2017). Similarly, the university miscellaneous Act, 2007 as amended provides for institutional university autonomy which confers power on the university senate to establish programs in the universities. Therefore, the expanded functions of NUC appears not to be in harmony with the University Act, 2007 as amended. This situation has implications for NUC's operations in terms of achieving quality university education in Nigeria. However, the multiple tasks of the NUC, NBTE and NCCE from their original advisory roles to the federal government on the matters bordering on tertiary institutions to multiple functions have implications for the effective performance of the bodies in achieving quality of education needed of the country.

Inadequate resources: quality of higher education is dependent on the quality of human and material resources put in place in an institution of higher learning such as lack of infrastructures, laboratories, workshops, libraries, students' hostel and electricity affects the quality of education. For quality delivery, these facilities need to meet the minimum standards of NUC, NBTE and NCCE in their respective institutions (Asiyai, 2015).

Lack of information communication technology facilities in institutions of higher learning: as part of education reform effort in 2010 Nigerian government adopted information communication technologies in all levels of education, but most of institutions of higher learning in the country are not linked with functional internet connectivity. Therefore, these challenges have disrupt the pace of quality assurance in higher education in Nigeria.

\subsection{The Balance between Accountability and Improvement of the QA Agencies}

\section{Accountability and improvement}

In an institution of higher education, the most controversial debate raised about the role of QA system to say, what is the most essential achievement of QA in an institution?, is it meeting the minimum standards or improving the quality of the institutions?

QA system in Vietnam has encouraged higher education institutions to develop their strength through self-assessment and self-accreditation policies. Therefore, compliance to standards was never an issue to focus on by the VQA but the accreditation system with internal QA and quality culture building which is regarded as a key element of the QA system, after VQA will then investigate, verify and validate the results. Thus, accountability and improvement of the situation have triggered the development of external QA in higher education.

Malaysia has encouraged higher education institutions to develop their strength through self-accreditation policies. Thus, similar to Vietnam compliance to standards was never an issue to focus on by the MQA but the accreditation system with internal QA and quality culture building which is regarded as a key element of the QA system. Accountability and improvement are dichotomous concepts where according to (Martin, 2018), the situation has first triggered the development of external QA mechanisms in higher education as a general reform movement.

Today, both Vietnam and Malaysia, higher education system and institutions are exposed more than ever to constant change and transformation. The government are increasingly engaged in the quality control of higher education institutions and or their programs through periodic external assessments but higher education institutions are also responding to quality concerns by setting up internal QA mechanisms for of monitoring and management (Higher education law, 2018), and in Vietnam an a periodic every 5 years will be re-inspection. Institutions were involved in QA practices based on the principles of responsibility, accountability and transparency through policies, procedures and mechanisms for regular reviewing and updating of its structure, functions, strategies and core activities to ensure continual quality improvement (COPPA, 2018).

The Nigerian QA agencies, achievement is to have both accountability and improvement but the agencies, focus was to ensure compliance to minimum standards and there are responses from public and institutional criticisms. Higher education institutions are far away from improvement and there is public worries towards the plight of QA in higher education institutions. According to (Banji, 2017), external review claims to encourage improvement whereas in fact, improvement has been a secondary feature, so it is necessary to examined claims for improvement through provisions for the challenges around the QA systems. He stated that there is a need for a paradigm shift because of the changes in fancy external QA in enhancing improvement. The shift in quality evaluation, towards how institutions might be encouraged in their efforts to develop a focus on mechanism and arrangement for quality enhancement. However, Vietnamese VQA and Malaysian MQA are experiencing accountability being demonstrated for continuous improvements while in Nigeria accountability is seen and 
invisible improvement.

\section{QA system autonomy}

Vietnam, internal QA is self- accreditation system, this process has not yet involved external QA agency. The higher education institutions more especially universities have a choice in selecting their internal QA approaches which include self- accreditation according to state-issued standards, this has encouraged higher education institutions autonomy, and in accordance with Vietnam's higher education law in 2019, universities are given administrative and financial autonomy for academic excellence (Higher education law \& Ministry of Education and Training).

Malaysia, internal QA is embedded within the self-accreditation system, as such reduced much involvement of external QA agency. The higher education institutions more especially universities have a choice in selecting their internal QA approaches which include self- accreditation. Malaysia, self-accreditation policy in the MQA document encouraged higher education institutions, autonomy. This is by following the universities and university colleges' Amendment Act, 1996 and Act, 2009 amen dent, universities are given administrative and financial autonomy to chart programs necessary for academic excellence. Where some universities have tried to developing objectives evaluation standards, selecting peer reviewers to ensure consistent judgments across reviews.

Nigeria, autonomy bothers on the relationship between the university and the government, it is varied in operational detail, in the degree to which they are applied in different countries and within countries and different types of institutions. Autonomy has been influenced by socio-economic and political factors, autonomy has been a thing of a struggle between institutions and government. The worries of stakeholders are an issue of the universities' autonomy and academic freedom which is at the level of interference from government and the internal governance of the universities in the performance of its traditional functions. NUC, NBTE and NCCE provides guidelines for higher education institutions to assist programs to build their internal QA mechanisms and internal QA was assessed through the guidance of external QA. However, there have been challenging between the external regulations (external QA) and the higher education institutions, internal QA on the issue of autonomy and academic freedom. According to (Asiyai, 2015), stated that self- improvement to enhance objectivity and fairness was discouraged by universities from the struggle of autonomy which supposed to have been things of the past rather than a great struggle between the university union ASUU and the agencies (external QA bodies). To that end, the balance between autonomy and regulation agencies is a continuous issues that need to be resolved to give room for quality education through quality assurance systems.

\section{Future of QA reform}

Whenever the issue of reforming QA is raised, there are voices against it. Therefore, evident has made it clear, collected and experience is analyzed as well, the applicable theories have explained ways to offer a rational response to the opposing views. Nigeria needs to gear more efforts to defeat the reform obstacles generated from the interest or politics around the QA systems. However, from the empirical studies on educational reforms of the European countries, it was justified that successful QA mechanisms of other countries can be applied to a different system, this is the common way most developing countries' QA system were improved through emulation to better their own QA systems. The model and framework of higher education institutions' QA should be based on theory and practice so that the methodology, management approaches and strategies are followed to ensure the quality of the higher education institutions. The government needs to mandate all the tertiary institutions to evaluate internal QA in compliance with the NPE 2013 and to emphasize quality improvement through internal QA systems. The three agencies NUC, NBTE and NCCE should plan to implement follow up evaluation in their respective institutions so that higher education programs should be encouraged to have a policy and procedure for continuous quality improvement (Adepoju, 2017).

\section{Limitation of $Q A$ systems}

Looking back on the QA agencies currently active in Nigeria's higher education institutions, it is easy to find out that they are having shortcomings that prevent them from offering sufficient services to tackle the quality issues in Nigeria higher education systems. The federal government is the decisive player in QA of institutions in Nigeria, but the problem with the national authorities' judgment of the quality of higher education institutions is it tends to focus on the national needs, unconsciously sacrifices the interest of other stakeholders. The consequences of the national QA are that it decreases tertiary institutions, autonomy more especially university who by amended Act, 2007 supposed to be autonomous and were not (Banji, 2017). This is because the agencies are too intimate with the government and agencies were categorized as the external QA bodies. Therefore, in a nutshell government is the major player in QA of the higher education in Nigeria and the external quality players 
are functioning under the umbrella of the government.

\section{Conclusion and Suggestion}

This comparison resulted in identifying some challenging aspects of QA systems that are crucial to ensure the quality of academic programs. Higher education system and policy, QA systems and framework and challenges associated with the QA systems were discussed in this study. Higher education system is continuous to ensuring the QA system and standards so that the academic provisions are not compromised. In the comparison of the QA system of the three countries demonstrated, there were variations and similarities in their structure and procedure which found that the QAs and frameworks were based on the government-led approach. Though they have different QA structures multi and single QA Vietnam, Nigeria and Malaysia respectively but focuses towards meeting their countries higher education institutions quality standards. However, the internal QA in Nigeria has been a key issue because of inadequate funding being the major bottleneck on the institutions' QA systems. Though there are many challenges in the QA process across the globe which depends on the country to country and from institution to institution. But at the global level countries need to demonstrate their education system to match with class standards; because the meeting international standards is no longer an option or an aspiration, it has become a necessity. Higher education institutions' QA system should face with a monitoring system that demands accountability, academics will have to comply with requirements in such a way as to minimize academic institutions disruption. Higher education QA's institution in Nigeria especially NUC and the universities amendment Acts on autonomy and freedom of university need to be reformed to give room for sound academic quality. To sum up, the challenges issues the government of Nigeria needs to reform her QA institutions so the higher education institutions should be accountable for Nigerian QA that will meet up the internalization standards around the globe. Higher education institutions' accountability may be an initial impetus toward quality improvement. Regarding these matters, developing strategic mechanisms might be important and new regulations from government and agencies might be required considering the challenges around the QA systems. Therefore, in the course of this study, the most important element needed of QA institutions are reforming the institutions to suit internationalization and or to introduce competitive mechanisms such as professional accreditation or a tender public that will help to increase the quality standards to meet up with the rest of the world.

\section{Reference}

Adepoju, T. L. (2017). An Overview of the Existing Quality Assurance Criteria in Nigerian Higher Institutions and Policy Implications An Overview of the Existing Quality Assurance Criteria in Nigerian Higher Institutions and Policy Implications.

Adetunji, A. (2018). Measures For Quality Assurance In The Nigerian University System : Why The Model Has Failed. (September).

Ahmed, S., Ali, B., \& Arbab, A. M. (2018). Assessing quality of academic programmes: comparing different sets of standards. Quality Assurance in Education, 26(3), 318-332. https://doi.org/10.1108/QAE-09-2016-0051

Asiyai, R. I. (2015). Improving Quality Higher Education in Nigeria: The Role of Stakeholders. International Journal of Higher Education, 4(1), 61-70. https://doi.org/10.5430/ijhe.v4n1p61

Banji, F. J. (2017). External Quality in Higher Education: The Need for a Paradigm Shift.

Chang, D. W., Morshidi, S., \& Dzulkifli, A. (2018). Working Paper Economics. Towards a Developed Nation. YUSOF ISHAK INSTITUTE, 1-19.

Commonwealth of Learning COL (2017). Open Education Resources Policy for Higher Education in Nigeria. Creative Commons Attributions- Share ALIKE 4.0 Liences (International). Retrieved from http://creativecommons.org/liences/by-sa/4.0

COPPA. (2018). Code of Practice for Programs Accreditation 2nd Ed. Agensi kalayakan Malaysia (Malaysian Qualification Agency MQA) Malaysia. Retrieved from http://www2.Mqa.gov.my//QAD/gavisponduan/COPPA/020nd \%2.0Edition\%20(2017).pdf

Dada, M. S., Wunti, Y. I., \& Martin, T. (2017). Accreditation as the Quality Assurance in Nigeria Universities: The Challenges. International Journal of Advanced Research, 5(12), 500-508. http://dx.doi.org/10.21474/IJAR01/5984

De Vincenzi, A., Garau, A., \& Guaglianone, A. (2018). Has the Quality of Teaching and Learning Process Improved as a Result of the Implementation of Quality Assurance Coordinated by the State?. Routledge Quality in Higher Education, 24(1), 55-65. https://doi.org/10.1080/13538322.2018.1426382 
Endut, A. S., AbdMajid, F., Bakar Ibrahim, A., \& Ashari, H. (2018). Responsive Outcome Evaluation as an Internal Quality Assurance Mechanism Alternative at IHLs in Malaysia. Procedia Social and Behavioural, 90(10), 13-21. https://doi.org/10.1016/j.sbspro.2013.07.060

Geven, K., \& Maricut, A. (2015). A Merry go - around of Evaluation Moving from Administrative Burden to Reflection on Education and Research in Romania. In A. Curaj, L. Matei, R. Pricopie, J. Salmi \& P. Scott (Eds.), The European Higher Education area: Between Critical Reflections and Future Policies: Part II (pp. 665-684). Springer. https://doi.org/10.1007/978-3-319-20877-0_42

Grapragasem, S., Krishnan, A., \& Mansor, A. N. (2014). Current Trends in Malaysian Higher Education and Effects on Education Policy and Practice: An Overview. International Journal of Higher Education, 3(1), 85-93. https://doi.org/10.5430/ijhe.v3n1p85

Gross, J. M. S. (2018). The SAGE Encyclopedia of Educational Research Measurement and Evaluation. SAGE Publication, Inc. https:// dx.doi.org/10.4135/9781506326139

Higher education law. Retrieved from https://thuvienphapluat.vn/van-ban/giao-duc/Luat-Giao-duc-dai-hoc-sua-doi-388254.aspx

Jarvis, D. S. L. (2017). Regulating Higher Education: Quality Assurance and Neo-Liberal Managerialism in Higher Education - A Critical Introduction. Policy and Society, 33(3), 155-166. https://doi.org/10.1016/j.polsoc.2014.09.005

Kayode, S. A. (2018). Nigeria Higher Education: Birth and Growth. QS Asia News Network. Retrieved from http://qswownews.com/Nigeria-higher-education-birth-growth/

Kromydas, T. (2017). Rethinking Higher Education and its Relationship with Social Inequalities; Past Knowledge, Present State and Future Potential. Palgrave Communication, 3(1), 1-11. https://doi.org/10.1057/s41599-017-0001-8

Machumu, H. J., \& Kisanga, S. H. (2015). Quality Assurance in Higher Education Institutions: Lesson from Africa. Journal of Education and Practice, 5(16), 144-156.

Mahbub, R. (2017). Quality Assurance for Higher Education: Challenges in Sustaining Continuous Quality Improvement for Malaysian Universities. INTED2017 Proceedings, 1(April), 5204-5210. https://doi.org/10.21125/inted.2017.1214

Martin, M. (2018). How Internal Quality Assurance can Drive Success University World News For Global Window on Higher Education.

Ministry of Education and Training. Retrieved from https://thuvienphapluat.vn/van-ban/giao-duc/Thong-tu-12-2017-TT-BGDDT-kiem-dinh-chat-luong-co-so-gi ao-duc-dai-hoc-349575.aspx

Ministry of Education and Training. Retrieved from https://moet.gov.vn/thong-ke/Pages/thong-ke.aspx

Mokhtar, R., AbdulRahman, A., Othman, S. H., \& Mat, A. N. (2014). Malaysian Academic Quality Assurance System in the Context of Issues, Challenges and Best Practices. Knowledge Management International Conference (KMICe). Retrieved from http://www.kmice.cms.net

MQA. (2018). Malaysian Qualifications Framework 2nd Ed.

Noda, A., Yung, C. H. A., Shibui, S., \& Chi, C. H. (2018). Restructuring Quality Assurance Frameworks A Comparative Study between NIAD-QE in Japan and HEEACT in Taiwan. Higher Education Evaluation and Development, 12(1), 2-18. https://doi.org/10.1108/HEED-12-2017-0008

Odukoya, J. A., Bowale, E., \& Okunlola, S. (2018). Formulation and Implementation of Educational Policies in Nigeria. African Educational Research Journal, 5(1), 1-4. https://doi.org/10.30918/AERJ.61.17.059

Tavares, T., Sin, C., Videira, P., \& Amaral, A. (2017). Academics' Perceptions of the Impact of Internal Quality Assurance on Teaching and Learning. Routledge Assessment and Evaluation in Higher Education. http://dox.org/10.1080/02602938.2016.1262326

Unimna, F. A., \& Unimke, S. A. (2018). The Challenges of Quality Assurance in the Implementation of Secondary School Social Studies Curriculum in Nigeria. International Journal of Contemporary Social Science Education IJCSSE, 1(1), 176-183.

Williams, J. (2016). Quality Assurance and Quality Enhancement: Is there a Relationship?. Quality in Higher Education, 22(2), 97-102. https://doi.org/10.1080/13538322.2016.1227207 


\section{Copyrights}

Copyright for this article is retained by the author(s), with first publication rights granted to the journal.

This is an open-access article distributed under the terms and conditions of the Creative Commons Attribution license (http://creativecommons.org/licenses/by/4.0/). 